\title{
ESTIMATION MODEL OF TRANSFORMER IRON LOSS USING NEURAL NETWORK
}

\author{
Tai-Ken Lu \\ Department of Electrical Engineering, National Taiwan Ocean University, Keelung, Taiwan, R.O.C., \\ tklu@mail.ntou.edu.tw \\ Chien-Ta Yeh \\ Department of Electrical Engineering, National Taiwan Ocean University, Keelung, Taiwan, R.O.C. \\ Min-Doon Dirn \\ Department of Electrical Engineering, National Taiwan Ocean University, Keelung, Taiwan, R.O.C.
}

Follow this and additional works at: https://jmstt.ntou.edu.tw/journal

Part of the Electrical and Computer Engineering Commons

\section{Recommended Citation}

Lu, Tai-Ken; Yeh, Chien-Ta; and Dirn, Min-Doon (2010) "ESTIMATION MODEL OF TRANSFORMER IRON LOSS USING NEURAL NETWORK," Journal of Marine Science and Technology: Vol. 18: Iss. 1, Article 6.

DOI: $10.51400 / 2709-6998.1864$

Available at: https://jmstt.ntou.edu.tw/journal/vol18/iss1/6

This Research Article is brought to you for free and open access by Journal of Marine Science and Technology. It has been accepted for inclusion in Journal of Marine Science and Technology by an authorized editor of Journal of Marine Science and Technology. 


\title{
ESTIMATION MODEL OF TRANSFORMER IRON LOSS USING NEURAL NETWORK
}

\author{
Tai-Ken Lu*, Chien-Ta Yeh*, and Min-Doon Dirn*
}

Key words: transformer, iron loss, neural network.

\begin{abstract}
When we want to calculate the transformer iron loss in operation, in addition to considering the nonlinear hysteretic phenomenon of transformer itself and the natural unbalanced characteristic, the actual situation that the transformer is operated under three phase unbalance state should also be considered. This results in very non-regular change of the transformer iron loss, and the accuracy of the polynomial model that is commonly used to estimate the iron loss of the transformer in the past is thus reduced. Since neural network has parallel processing capability, which can process highly nonlinear function problem, hence, in this study, we try to use neural network model to set up the nonlinear relationship between the iron loss and voltage of the transformer. Therefore, we can only measure the voltage value to get accurate transformer iron loss.

As we compare the neural network model set up in this study to the conventional polynomial method, we can find that neural network model has lower average error rate; this is especially in the prediction of the total transformer iron loss in the three phase balance system, and it is found that the prediction error can be reduced by $50 \%$.
\end{abstract}

\section{INTRODUCTION}

Since the global population keeps increasing and every industry keeps growing, the global consumption on energy thus doubles; however, the storage of these fossil fuels is limited and will get exhausted for sure someday. In addition, massive use of petrochemical fuel could also cause climate change and endanger the environment and ecology, hence, in order to reduce the green house gas release as promised by each country in the Kyoto Protocol and to reduce the energy shortage pressure, each country has to devote to the enhance of energy utilization efficiency.

Paper submitted 04/20/08; revised 12/21/08; accepted 01/21/09. Author for correspondence: Tai-Ken Lu (e-mail: tklu@mail.ntou.edu.tw).

*Department of Electrical Engineering, National Taiwan Ocean University, Keelung, Taiwan, R.O.C.
To electric power system, in addition to the copper loss in power transmission and distribution loss, another loss that occupies a larger proportion is the transformer loss. Transformer loss can be divided into two parts such as iron loss and copper loss; although copper loss is larger, yet it will be generated only when it is loaded; however, although iron loss is smaller, yet it will be generated for 24 hours as long as the transformer is added with voltage; hence, iron loss occupies a pretty large proportion in transformer loss.

In the past, studies related to the iron loss of transformer can be roughly divided into (1) Measurement method [2, 3, 14, 17, 18], (2) Finite Element Method [1, 13, 15, 19], (3) Equivalent circuit method $[7,8,12,16,20]$, and (4) Neural network method $[4,5,6,9,10,11]$; among them, equivalent circuit method is applied in the real operation analysis, and the measurement method, finite element method and neural network are commonly used in the analysis of the effect on the iron loss of the transformer in the past when transformer core material and structure is changed. All the above mentioned literature does not investigate in depth the effect on the iron loss of the transformer by the three phase non-equilibrium factor

In the past, literature that uses neural network method to investigate the iron loss of the transformer is mostly in the design and manufacturing of transformer; in this study, we try to apply neural network in the real operation of transformer. We try to use neural network model to set up the nonlinear relationship between iron loss and voltage of transformer. Therefore, we only need to measure voltage value to get accurate iron loss of the transformer.

This model can evaluate the iron loss of on-line transformer under three phase balanced/unbalanced system, then it can estimate the contribution that the three phase load reorganized to the carbon reduction and energy saving.

\section{TRANSFORMER}

When we are about to estimate the transformer iron loss in operation, factors that have to be considered include the nonlinear magnetization characteristic of the core of the transformer itself, the natural unbalanced characteristic of three phase transformer, as well as the situation that the voltage of the alternating current system is not of fixed value 


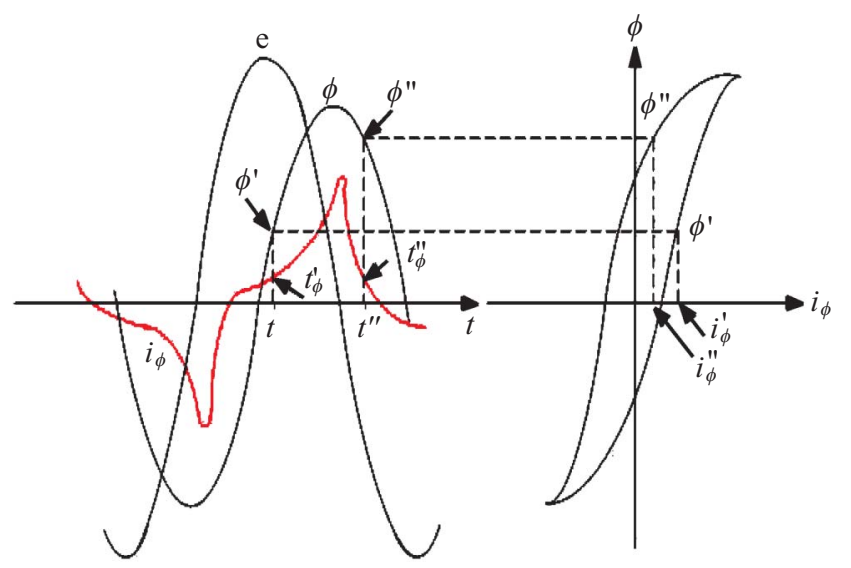

Fig. 1. Excitation phenomenon.

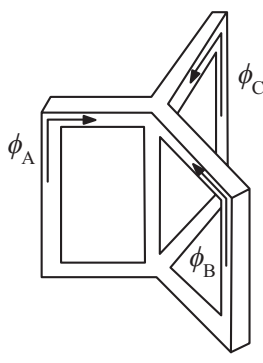

(a)

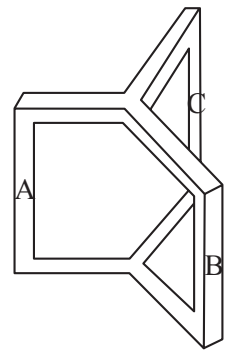

(b)

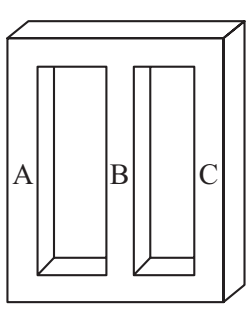

(c)
Fig. 2. The evolvement of three phase core-type transformer.

but will change slightly along with the size of the loading. In the following, we will make a detailed description by aiming at the nonlinear characteristic of the transformer itself:

\section{Nonlinear Magnetization Characteristic of Core}

Due to the nonlinear hysteresis and saturation characteristic of the core of transformer, when transformer is excited by AC voltage, the waveform of the exciting current, $i_{\phi}$, will have a sudden change and be different from the voltage sine wave (As shown in Fig. 1). This nonlinear magnetization characteristic will make it more difficult to estimate the iron loss of transformer.

\section{Three Phase Transformer Natural Unbalanced Characteristic}

During the development process of three phase transformer, it is first three single phase core-type transformer as shown in Fig. 2(a), and each transformer is similar to single phase transformer. If the electromotive force of these transformers are balanced sine waves, then the magnetic fluxes $\phi_{a}, \phi_{b}, \phi_{c}$ will be balanced sine waves too, and the total magnetic flux that passes through the core legs of these magnetic fluxes will be zero, hence, the core leg can be neglected as shown in Fig. 2(b). However, since core is formed by stacked pieces, hence, it is easier to be manufactured by using the linear arrangement structure as shown in Fig. 2(c). From the core structure of Fig. 2(c), it can be seen that the magnetic path of $A$ and $C$ part is slightly longer than that of $B$, hence, $\mathrm{A}, \mathrm{B}, \mathrm{C}$ phases are not totally symmetrical, and this is the reason of the natural unbalanced characteristic of the three phase transformer.

\section{THE IRON LOSS MODEL OF TRANSFORMER}

\section{Polynomial Representation of the Transformer Iron Loss}

In conventional way of calculation, the transformer iron loss is divided into hysteresis and eddy current loss for respective calculation. However, magnetic flux density is not as easy to be measured as voltage, hence, many people proposed respectively polynomials that use voltage as the independent variable for the calculation. The past researches can be roughly divided into the following three models:

Polynomial model 1 [11]:

$$
P_{\text {core }}=\frac{\text { KVA Rating }}{\text { System Base }}\left(A V^{2}+B e^{C V^{2}}\right)
$$

Polynomial model 2 [14]:

$$
P_{\text {core }}=\left(C_{o}^{\prime}+C_{a}^{\prime} \phi_{p u}^{4}\right) V^{2}
$$

Polynomial model 3 [15]:

$$
P_{\text {core }}=C_{6} V_{6}+C_{5} V_{5}+C_{4} V_{4}+C_{3} V_{3}+C_{2} V_{2}+C_{1} V+C_{0}
$$

Here $P_{\text {core }}$ is the per-unit value of iron loss of transformer, $V$ is the per-unit value of the operation voltage of transformer, $\phi_{p u}$ is the per-unit value of magnetic flux, $A, B, C_{i}, C_{j}$ are respectively the coefficient of each model.

\section{Neural Network Model of the Transformer Iron Loss}

The neural network model of three phase voltage and three phase iron loss (Model I): In this model, A, B, C three phase voltages are used as the three inputs of the neural network, and the three phase iron losses are three output terms.

The neural network model of three phase voltage and total iron loss (Model II): In this model, A, B, C three phase voltages are used as the three inputs of the neural network, and the three phase total iron loss is the output term.

The neural network model of voltage of each phase and iron loss of each phase (Model III): In this model, the neural network model for the voltage and iron loss of each phase is set up respectively; the phase voltage is used as one input term of the neural network and phase iron loss is used as one output term. 


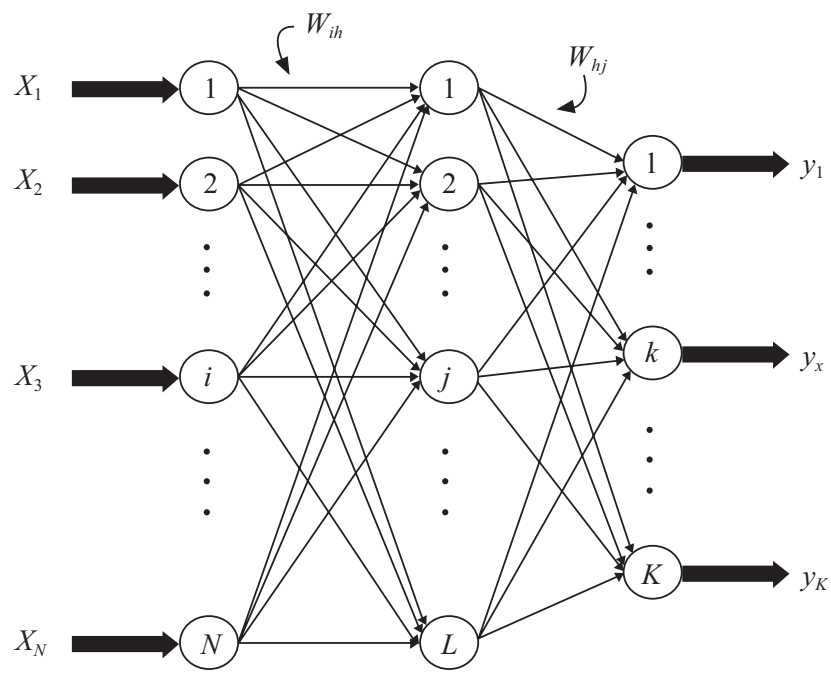

Fig. 3. The architecture of back-propagation network.

\section{NEURAL NETWORK}

\section{Introduction to Back-Propagation Networks}

In 1985, Rumelhart Mcclelland added a buried layer to the back-propagation network and change the operation function into smooth and differentiable transfer function, the backpropagation network that is mostly used currently is thus formed; back-propagation network can process the exclusive OR (which is abbreviated as XOR) issue that the back-propagation model can not handle.

Back-propagation network is a multiple layer feed-forward network that has learning capability; the concept of the gradient steepest descent method is used to adjust the parameter, then after iterative operation, the error is minimized and the most accurate solution is obtained.

Since back-propagation network has higher learning accuracy and faster recall speed, the output value can be continuous and complicated sample identification as well as highly nonlinear function issue can be handled. Therefore, backpropagation network is the most representative one among the current neural network learning models and is the most used neural network.

\section{Network Architecture of Back-Propagation Network}

Figure 3 is the architecture of back-propagation network, where there are $N$ neural units in the input layer, $L$ neural units in the buried layer and $K$ neural units in the output layer; here the number of neural unit in the buried layer will be dependent on the problem and there is no specific method to decide it; usually, the optimum number is found by trial and error method.

\section{Network Operation of Back-Propagation Network}

Back-propagation network is a way of setting up mapping input value and output value; it assembles simple and

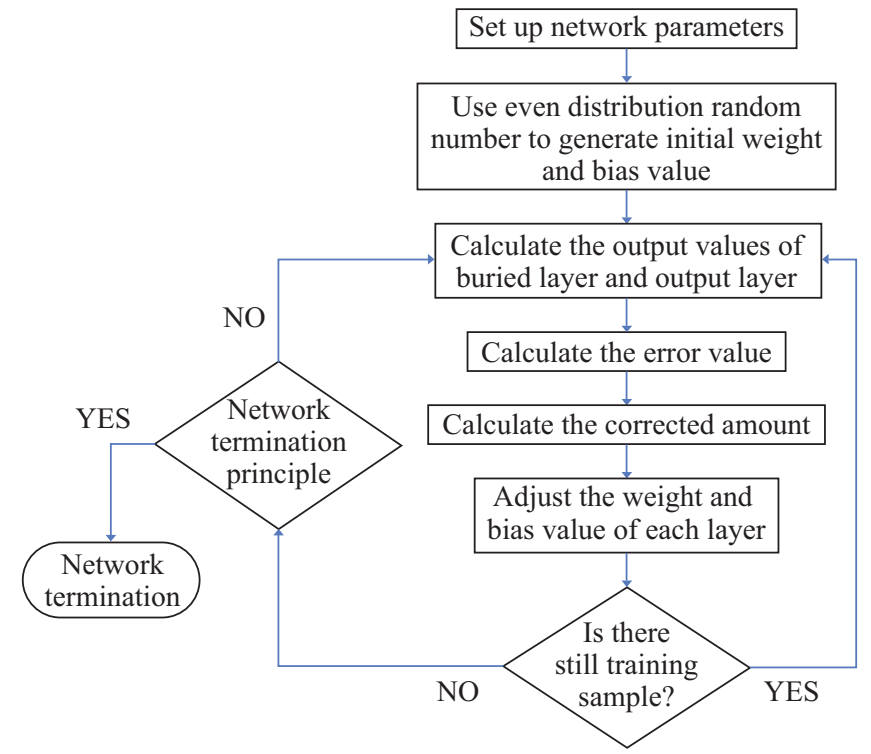

Fig. 4. The learning process flow of back-propagation network.

nonlinear function, and after many times of assemblies, a complicated function form is set up to solve the complicated mapping issue. Figure 4 is the learning process flow of backpropagation network.

\section{MEASUREMENT OF THE TRANSFORMER IRON LOSS}

\section{Measurement of Three Phase Balance System}

Since in real AC system, voltage is not fixed but will have slight change along with the change of the loading and the amplitude of change is about within $\pm 10 \%$ of the nominal voltage; therefore, in this study, the iron loss change of the transformer within $\pm 10 \%$ of the nominal voltage will be measured. Figure 5 is the iron loss measurement process flow of the transformer under three phase balance system. The transformer for experimental use is Shihlin three phase, 10KVA, 11400V/120V transformer. The standard power supply is Elgar 5200.

\section{Measurement of Three Phase Unbalance System}

Since the load connected to real three phase AC system will not be the same, hence, three phase transformer is operating under three phase unbalance. However, the voltage combination for three phase unbalance is infinite, and in order to distribute evenly all kinds of three phase unbalance voltage combinations, this study divides $90 \%$ nominal voltage to $110 \%$ nominal voltage into three sections, hence, there will be 27 configurations for the three phase voltage, and 10 three phase unbalance voltages will be taken randomly from each configuration to perform the experiment. Figure 6 is the measurement process flow of the transformer iron loss under three phase unbalance system. 


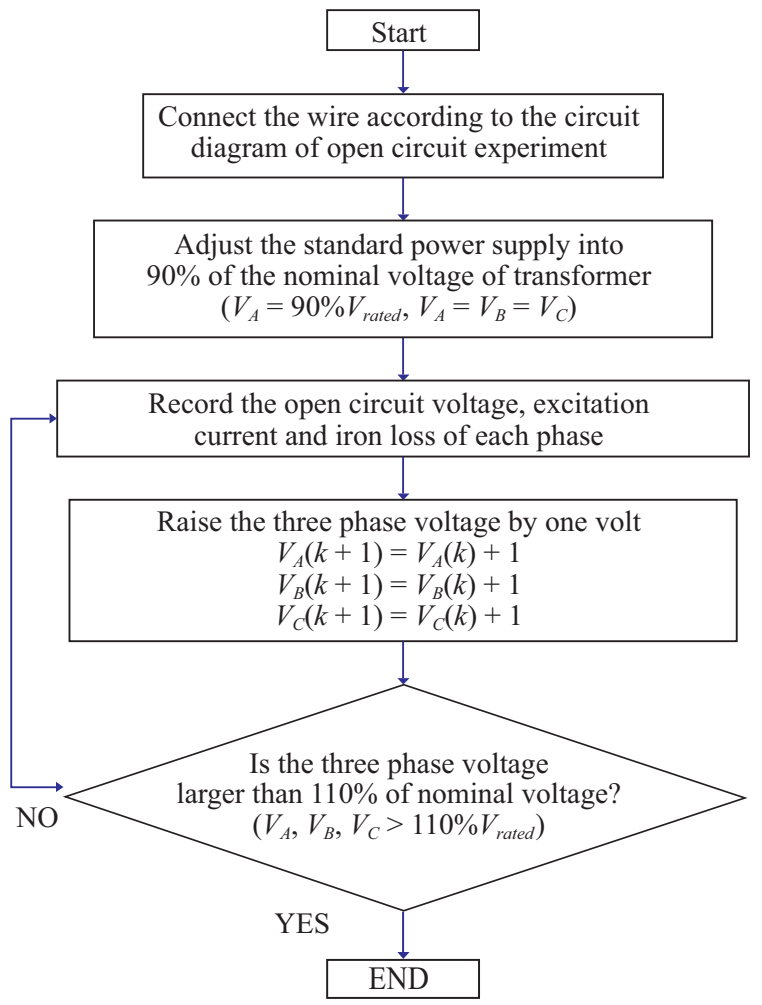

Fig. 5. The experimental flow of open circuit of transformer under three phase balance system.

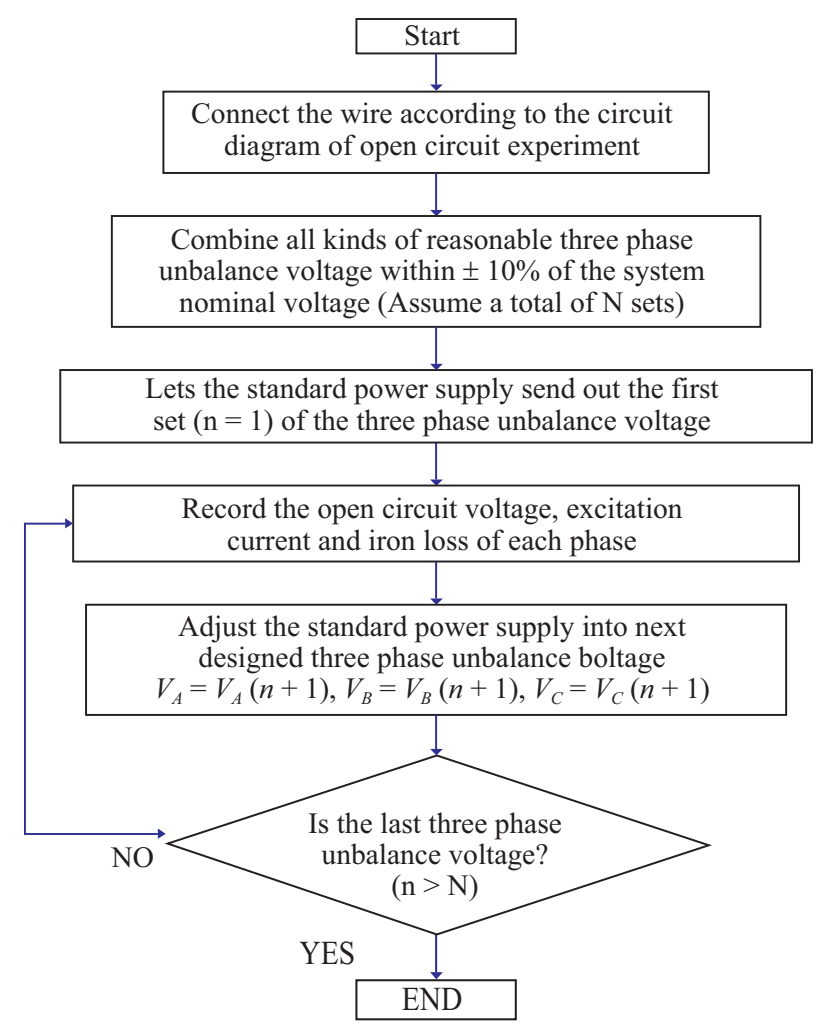

Fig. 6. The experimental process flow of open circuit of transformed under three phase unbalance system.

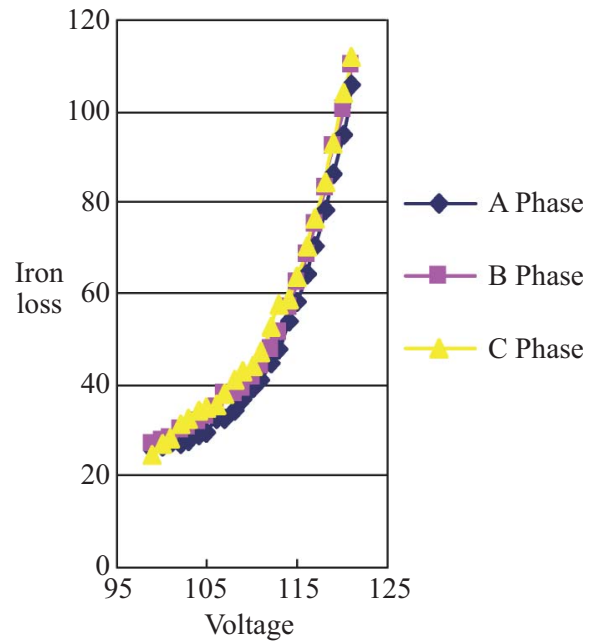

Fig. 7. The relationship between iron loss value and voltage of each phase of the transformer.

\section{IRON LOSS MEASUREMENT AND ANALYSIS FOR TRANSFORMER}

\section{Three Phase Balance System}

Figure 7 shows the relationship between the iron loss and voltage of each phase of transformer. It can be seen from the figure. that even under three phase balance system, the iron loss value of each phase of the transformer is not the same; meanwhile, the larger the voltage, the larger the difference of the three phase iron loss value. In addition, we can also that the iron loss value of each phase will increase with the increase in the voltage; among them, the A phase iron loss change is the most regular one and $\mathrm{C}$ phase iron loss change is the most irregular. There are a total of 57 measurement data.

\section{Three Phase Unbalance System}

In this study, one of the configurations $\left(V_{a} \in[107,114]\right.$, $\left.V_{b} \in[114,121], V_{c} \in[99,107]\right)$ is randomly taken for 10 sets of three phase unbalance voltage experimental measurement results and listed in Table 1; it can be seen from the experimental data in the table that under three phase unbalance system, the different mutual inductance voltage of each phase of the transformer has resulted in more irregular change of the iron loss. Therefore, it is very difficult to use general method to acquire accurate iron loss for the operation of transformer under three phase unbalance system.

\section{SIMULATION RESULT ANALYSIS}

\section{Three Phase Balance System}

In this study, three different types of transformer iron loss neural network models will be used for the simulation and analysis. Meanwhile, the accuracy, training time and the average prediction error rate of these three neural network 
Table 1. The iron loss measurement result under three phase unbalance system.

\begin{tabular}{|c|c|c|c|c|c|c|c|c|c|c|}
\hline & 1 & 2 & 3 & 4 & 5 & 6 & 7 & 8 & 9 & 10 \\
\hline $\mathrm{Va}$ & 113.24 & 112.09 & 110.07 & 109.96 & 113.09 & 109.34 & 107.81 & 108.81 & 112.80 & 111.84 \\
\hline $\mathrm{Vb}$ & 115.16 & 118.43 & 116.39 & 114.12 & 119.13 & 120.76 & 117.05 & 115.85 & 117.52 & 114.49 \\
\hline $\mathrm{Vc}$ & 105.32 & 101.19 & 100.26 & 104.55 & 103.86 & 104.68 & 99.95 & 106.19 & 104.00 & 103.29 \\
\hline $\mathrm{Pa}$ & 54.90 & 63.50 & 49.30 & 44.70 & 66.00 & 64.80 & 48.60 & 51.80 & 54.80 & 53.10 \\
\hline $\mathrm{Pb}$ & 39.40 & 37.90 & 40.30 & 36.42 & 43.60 & 46.80 & 37.60 & 41.60 & 43.40 & 35.51 \\
\hline $\mathrm{Pc}$ & 41.75 & 38.88 & 31.74 & 36.58 & 42.90 & 40.71 & 31.38 & 33.70 & 42.55 & 36.18 \\
\hline
\end{tabular}

Table 2. The training result of neural network model I.

\begin{tabular}{|c|c|c|c|c|c|c|c|c|}
\hline $\begin{array}{l}\text { Number of neural } \\
\text { unit in first buried }\end{array}$ & $\begin{array}{l}\text { Number of neural } \\
\text { unit in second }\end{array}$ & $\begin{array}{l}\text { Number of } \\
\text { iteration }\end{array}$ & $\begin{array}{l}\text { Training } \\
\text { time }\end{array}$ & Accuracy & \multicolumn{3}{|c|}{$\begin{array}{l}\text { Single phase predicted } \\
\text { average error }(\%)\end{array}$} & $\begin{array}{l}\text { Three phase } \\
\text { predicted average }\end{array}$ \\
\hline 80 & 25 & 30000 & $4 \mathrm{~min}$ & $3.87241 \times 10^{-5}$ & 1.18 & 1.19 & 3.85 & 2.07 \\
\hline 90 & 25 & 30000 & $4 \mathrm{~min}$ & $2.69858 \times 10^{-5}$ & 0.89 & 1.46 & 3.49 & 1.95 \\
\hline 95 & 25 & 30000 & $4 \min$ & $1.61946 \times 10^{-5}$ & 0.94 & 1.19 & 3.67 & 1.93 \\
\hline 97 & 25 & 30000 & $4 \mathrm{~min}$ & $3.67521 \times 10^{-5}$ & 1.43 & 1.62 & 2.64 & 1.90 \\
\hline 100 & 25 & 30000 & $4 \min$ & $1.84568 \times 10^{-5}$ & 0.96 & 1.58 & 3.44 & 1.99 \\
\hline 110 & 25 & 30000 & $4 \min$ & $1.32434 \times 10^{-5}$ & 0.89 & 1.53 & 3.84 & 2.08 \\
\hline 120 & 25 & 2914 & $40 \mathrm{sec}$ & $9.99737 \times 10^{-6}$ & 0.76 & 1.29 & 4.22 & 2.09 \\
\hline 200 & 25 & 11125 & $2 \min$ & $9.94484 \times 10^{-6}$ & 1.04 & 1.59 & 3.72 & 2.12 \\
\hline 97 & 10 & 30000 & $4 \mathrm{~min}$ & $1.5733 \times 10^{-5}$ & 0.94 & 0.82 & 4.49 & 2.08 \\
\hline 97 & 15 & 30000 & $4 \min$ & $4.6379 \times 10^{-5}$ & 0.43 & 1.39 & 2.97 & 1.60 \\
\hline 97 & 20 & 30000 & $4 \mathrm{~min}$ & $1.108 \times 10^{-4}$ & 0.64 & 2.08 & 2.10 & 1.61 \\
\hline 97 & 25 & 30000 & $4 \mathrm{~min}$ & $3.67521 \times 10^{-5}$ & 1.43 & 1.63 & 2.64 & 1.90 \\
\hline 97 & 30 & 30000 & $4 \min$ & $2.2498 \times 10^{-5}$ & 0.56 & 1.30 & 3.53 & 1.80 \\
\hline 97 & 35 & 30000 & $4 \mathrm{~min}$ & $1.0351 \times 10^{-5}$ & 0.41 & 1.52 & 3.44 & 1.79 \\
\hline
\end{tabular}

deductions will be compared; moreover, the result will be compared to all kinds of polynomial models as proposed in the literature.

Table 2 is the training result of model I neural network. Here three phase average error rate is used to adjust the number of neural unit in the buried layer. Since the prediction and estimation of single layer buried layer is worse, hence, in this study, two layers of buried layer are adopted to set up neural network model. First, the number of neural unit in second buried layer is fixed at 25 , then different number of neural unit of first layer is tried, and it is found that the average error rate of $1.898171 \%$ when the first layer is of 97 neural unit is minimum. Next, we fix the first buried layer at 97 neural units and let the second buried layer neural unit number vary from 10 to 35 with interval of five neural units for the testing of average error rate, then it can be found that when the second buried layer is of 15 neural units, the average error rate is minimum. Therefore, the model architecture of model I neural network is: input layer composes the three neural units for the input of A, B, C phase voltage; the first buried layer is of 97 neural units, the second buried layer is of 15 neural units, and the output layer composes three neural units for the output of A, B, C phase iron loss value. Model II and model III are set up by the same steps. The number of neural unit is as shown in Table 3. The training sample number is 23 and the verification sample number is 2 .

In Table 3, under three phase balance system, all the major parameters of the neural network models of three transformer iron losses are compared. It can be seen from the table that the training time for model III is the shortest and the network response is the best, which is because the relationship between voltage of each phase and iron loss of each phase is simpler. On the contrary, the relationship of model I is more complicated and the time needed for the training is thus longer and the network response is worse as well as a higher prediction error rate.

However, the total iron loss has the most obvious change along with voltage and the change is more regular, hence, model II has the lowest prediction error rate.

Table 4 is a comparison among neural network model II and three polynomial models under three phase balance system, wherein the coefficient of the polynomial is obtained through the least square method. By comparing the result, it can be seen that the error rate by using neural network to estimate the 
Table 3. The training comparisons of all kinds of neural network models under three phase balance system.

\begin{tabular}{|l|c|c|c|c|c|}
\hline & \multirow{2}{*}{ Model I } & \multirow{2}{*}{ Model II } & \multicolumn{3}{|c|}{ Model III } \\
\cline { 3 - 6 } & & & A & B & C \\
\hline Number of neural unit in first buried layer & 97 & 97 & 50 & 50 & 40 \\
\hline Number of neural unit in second buried layer & 15 & 21 & 5 & 10 & 10 \\
\hline Number of iteration & 30000 & 30000 & 4059 & 5206 & 4969 \\
\hline Training time & $4 \mathrm{~min}$ & $4 \mathrm{~min}$ & $15 \mathrm{sec}$ & $15 \mathrm{sec}$ & $15 \mathrm{sec}$ \\
\hline Accuracy $\left(\times 10^{-5}\right)$ & 4.638 & 1.646 & 1.0 & 1.0 & 1.0 \\
\hline Predicted average error $(\%)$ & 1.596 & 0.588 & 0.185 & 0.821 & 1.587 \\
\hline
\end{tabular}

Table 4. Comparisons between neural network model 2 and three polynomial models under three phase balance system.

\begin{tabular}{|l|l|c|}
\hline \multicolumn{1}{|c|}{ Estimation model } & & Error $(\%)$ \\
\hline Polynomial model 1 & $P_{\text {core }}=\frac{10 \mathrm{KVA}}{10 \mathrm{KVA}}\left(0.007 V^{2}+0.020 e^{0.00063965 V^{2}}\right)$ & 1.25 \\
\hline Polynomial model 2 & $P_{\text {core }}=\left(-0.006+\left(1.22 \times 10^{-10}\right) V^{4}\right) V^{2}$ & 11.02 \\
\hline Polynomial model 3 & $P_{\text {core }}=\left(-5.43 \times 10^{-7}\right) V^{6}+(0.0002) V^{5}-0.013 V^{4}-4.25 V^{3}+853.38 V^{2}-59143 V+1.47 \times 10^{6}$ & 1.06 \\
\hline Neural network model II & $P_{\text {core }}$ & 0.59 \\
\hline
\end{tabular}

Table 5. Comparisons between neural network model 3 and three polynomial models under three phase balance system.

\begin{tabular}{|c|c|c|}
\hline Estimation model & & Error $(\%)$ \\
\hline \multirow{3}{*}{ Polynomial model 1} & $P_{\text {core }, A}=\frac{10 \mathrm{KVA}}{10 \mathrm{KVA}}\left(0.002 V^{2}+0.004 e^{0.00067 \mathrm{~V}^{2}}\right)$ & 1.71 \\
\hline & $P_{\text {core }, B}=\frac{10 \mathrm{KVA}}{10 \mathrm{KVA}}\left(0.002 V^{2}+0.006 e^{0.00065 V^{2}}\right)$ & 0.93 \\
\hline & $P_{\text {core }, C}=\frac{10 \mathrm{KVA}}{10 \mathrm{KVA}}\left(0.002 V^{2}+0.013 e^{0.0006 V^{2}}\right)$ & 2.01 \\
\hline \multirow{3}{*}{ Polynomial model 2} & $P_{\text {core }, A}=\left(-0.002+\left(3.96 \times 10^{-11}\right) V^{4}\right) V^{2}$ & 12.21 \\
\hline & $P_{\text {core }, B}=\left(-0.002+\left(4.09 \times 10^{-11}\right) V^{4}\right) V^{2}$ & 10.85 \\
\hline & $P_{\text {core }, C}=\left(-0.002+\left(4.17 \times 10^{-11}\right) V^{4}\right) V^{2}$ & 10.13 \\
\hline \multirow{3}{*}{ Polynomial model 3} & $P_{\text {core }, A}=\left(-3.91 \times 10^{-9}\right) V^{6}-\left(1.70 \times 10^{-5}\right) V^{5}+0.010 V^{4}-2.31 V^{3}+257.17 V^{2}-14224 V+3.13 \times 10^{5}$ & 0.88 \\
\hline & $P_{\text {core }, B}=\left(-6.75 \times 10^{-8}\right) V^{6}-\left(1.68 \times 10^{-5}\right) V^{5}+0.021 V^{4}-5.55 V^{3}+653.12 V^{2}-37068 V+8.27 \times 10^{5}$ & 1.31 \\
\hline & $P_{\text {core }, C}=\left(-8.95 \times 10^{-8}\right) V^{6}+\left(6.47 \times 10^{-5}\right) V^{5}-0.019 V^{4}+3.06 V^{3}-272.45 V^{2}+12948 V-256669$ & 2.54 \\
\hline \multirow{3}{*}{ Neural network model III } & $P_{\text {core }, A}$ & 0.19 \\
\hline & $P_{\text {core }, B}$ & 0.82 \\
\hline & $P_{\text {core }, C}$ & 1.59 \\
\hline
\end{tabular}

total transformer iron loss is about half of that of the polynomial model.

Table 5 is a comparison between neural network model III and three polynomial models under three phase balance system; among three polynomial models, model 3 has smaller $\mathrm{A}$ phase iron loss estimation error rate, that is, about $0.88 \%$, model 1 has smaller estimation error rates for $\mathrm{B}, \mathrm{C}$ phase iron losses, and the error rates are respectively $0.93 \%$ and $2.01 \%$; however, the use of neural network to estimate the iron loss value of each phase of transformer has error rates smaller than 
Table 6. Comparisons of all kinds of neural network models.

\begin{tabular}{|l|c|c|c|c|c|}
\hline & \multirow{2}{*}{ Model I } & \multirow{2}{*}{ Model II } & \multicolumn{3}{|c|}{ Model III } \\
\cline { 3 - 6 } & & & A & B & C \\
\hline Number of neural unit in first buried layer & 97 & 97 & 50 & 50 & 40 \\
\hline Number of neural unit in second buried layer & 15 & 21 & 5 & 10 & 10 \\
\hline Number of iteration & 30000 & 30000 & 4059 & 5206 & 4969 \\
\hline Training time & $4 \mathrm{~min}$ & $4 \mathrm{~min}$ & $15 \mathrm{sec}$ & $15 \mathrm{sec}$ & $15 \mathrm{sec}$ \\
\hline Accuracy $\left(\times 10^{-5}\right)$ & 4.638 & 1.646 & 1.0 & 1.0 & 1.0 \\
\hline Predicted average error rates $(\%)$ & 1.596 & 0.588 & 0.185 & 0.821 & 1.587 \\
\hline
\end{tabular}

Table 7. Comparisons of the error rate of model II and three polynomial models.

\begin{tabular}{|c|c|c|c|c|}
\hline Estimation model & & $\begin{array}{c}\text { Min } \\
\text { error }(\%)\end{array}$ & $\begin{array}{c}\operatorname{Max} \\
\text { error }(\%)\end{array}$ & $\begin{array}{l}\text { Avg } \\
\text { error }(\%)\end{array}$ \\
\hline $\begin{array}{l}\text { Polynomial } \\
\text { model } 1\end{array}$ & $P_{\text {core }, \text { Total }}=\frac{\text { KVA Rating }}{\text { System Base }}\left(-0.020 V^{2}+55.30 e^{0.00016 V^{2}}\right)$ & 2.64 & 22.34 & 9.62 \\
\hline $\begin{array}{l}\text { Polynomial } \\
\text { model } 2\end{array}$ & $\begin{aligned} P_{\text {core }, \text { Total }}= & \left(-0.011+\left(6.33 \times 10^{-11}\right) V_{a}^{4}\right) V_{a}^{2}+\left(0.012-\left(5.72 \times 10^{-12}\right) V_{b}^{4}\right) V_{b}^{2} \\
& +\left(-0.006+\left(5.94 \times 10^{-11}\right) V_{c}^{4}\right) V_{c}^{2}\end{aligned}$ & 2.35 & 13.31 & 6.00 \\
\hline $\begin{array}{l}\text { Polynomial } \\
\text { model } 3\end{array}$ & $\begin{aligned} P_{\text {core }, \text { Total }}= & \left(-5.02 \times 10^{-7}\right) V_{a}^{6}+\left(3.07 \times 10^{-4}\right) V_{a}^{5}-0.077 V_{a}^{4}+10.291 V_{a}^{3} \\
& -763.98 V_{a}^{2}+29974 V_{a}+\left(7.15 \times 10^{-7}\right) V_{b}^{6}-\left(2.79 \times 10^{-4}\right) V_{b}^{5}+0.024 V_{b}^{4} \\
& +4.24 V_{b}^{3}-983.6 V_{b}^{2}+70897 V_{b}+\left(6.40 \times 10^{-7}\right) V_{C}^{6}-\left(3.69 \times 10^{-4}\right) V_{C}^{5} \\
& +0.087 V_{C}^{4}-10.57 V_{C}^{3}+694.99_{C}^{2}-22808 V_{C}-2.01 \times 10^{6}\end{aligned}$ & 1.56 & 8.22 & 3.56 \\
\hline $\begin{array}{l}\text { Neural network } \\
\text { model II }\end{array}$ & $P_{\text {core }, \text { Total }}$ & 0.15 & 7.85 & 2.45 \\
\hline
\end{tabular}

those of three polynomial models, the error rates are respectively $0.19 \%, 0.82 \%$ and $1.59 \%$.

\section{Three Phase Unbalance System}

In this study, three different types of transformer iron loss neural network models will be used for the simulation and analysis; meanwhile, the accuracy, training time and the predicted average error rates of these three neural network deductions will be compared, and will be further compared to the result of polynomial model as proposed in the reference literature. There are 270 training samples in the neural network model, and 20 verification samples.

In Table 6, under three phase unbalance system, all the major parameters of the neural network models of three transformer iron losses are compared. It can be seen from the table that the training time for model II is the shortest, the network convergence response is the best and the prediction error rate is the lowest, which is because that the total iron loss shows the most obvious trend and more regular change along with the change in voltage. On the contrary, the relationship of model I is more complicated, hence, the time needed will be longer and the network convergence response is worse and the prediction error rate is higher.

Table 7 is a comparison of the error rates between model II and three polynomial models, among them, the coefficient of polynomial model is found by the least square method; among the polynomial models, model 3 has minimum error rate with average error rate of $3.56 \%$; however, the use of neural network for the prediction of total iron loss has an average error rate of $2.45 \%$. Table 8 is a comparison of the error rate of model III and those of three polynomial models, and among the three polynomial models, model 3 has minimum error rate, and the error rates are respectively $4.78 \%, 4.44 \%$ and $4.86 \%$; however, when neural network is used to predict the total iron loss of each phase of transformer, the error rates can be reduced to $3.32 \%, 4.02 \%$ and $4.29 \%$.

\section{CONCLUSION}

Since in real three phase AC system, the connected three phase loadings will not be the same, hence, three phase transformer operates under three phase unbalance state, which in turn makes the iron loss change of transformer very irregular. In this study, three different neural network models are used respectively to set up the nonlinear relationship between voltage and iron loss of the transformer under three phase system. After neural network operation, no matter in the prediction of the iron loss of each phase of the transformer or 
Table 8. Comparisons of the error rate of model III and those of three polynomial models.

\begin{tabular}{|c|c|c|c|c|}
\hline $\begin{array}{l}\text { Estimation } \\
\text { model }\end{array}$ & & $\begin{array}{l}\text { Min } \\
\text { error } \\
(\%)\end{array}$ & $\begin{array}{c}\text { Max } \\
\text { error } \\
(\%)\end{array}$ & $\begin{array}{l}\text { Avg } \\
\text { error } \\
(\%) \\
\end{array}$ \\
\hline $\begin{array}{c}\text { Polynomial } \\
\text { model } 1\end{array}$ & $\begin{array}{l}P_{\text {core }, A}=\frac{\text { KVA Rating }}{\text { System Base }}\left(0.004 V^{2}+\left(3.56 \times 10^{-7}\right) e^{0.0012 V^{2}}\right) \\
P_{\text {core }, B}=\frac{\text { KVA Rating }}{\text { System Base }}\left(0.004 V^{2}+377.78 e^{-0.00043 V^{2}}\right) \\
P_{\text {core }, C}=\frac{\text { KVA Rating }}{\text { System Base }}\left(0.004 V^{2}+\left(4.80 \times 10^{-10}\right) e^{0.0017 V^{2}}\right)\end{array}$ & 0.98 & 64.50 & 22.15 \\
\hline $\begin{array}{l}\text { Polynomial } \\
\text { model } 2\end{array}$ & $\begin{array}{l}P_{\text {core }, A}=\left(0.006+\left(1.73 \times 10^{-12}\right) V_{a}^{4}\right) V_{a}^{2}+\left(-0.0005+\left(1.26 \times 10^{-11}\right) V_{b}^{4}\right) V_{b}^{2}+\left(-0.007+\left(2.43 \times 10^{-11}\right) V_{c}^{4}\right) V_{c}^{2} \\
P_{\text {core }, B}=\left(-0.007+\left(1.71 \times 10^{-11}\right) V_{a}^{4}\right) V_{a}^{2}+\left(0.008-\left(1.06 \times 10^{-11}\right) V_{b}^{4}\right) V_{b}^{2}+\left(-0.003+\left(3.07 \times 10^{-11}\right) V_{c}^{4}\right) V_{c}^{2} \\
P_{\text {core }, C}=\left(-0.01+\left(4.44 \times 10^{-11}\right) V_{a}^{4}\right) V_{a}^{2}+\left(0.004-\left(7.68 \times 10^{-12}\right) V_{b}^{4}\right) V_{b}^{2}+\left(0.004+\left(4.43 \times 10^{-12}\right) V_{c}^{4}\right) V_{c}^{2}\end{array}$ & $\begin{array}{l}0.42 \\
2.28 \\
0.81\end{array}$ & $\begin{array}{l}17.08 \\
16.69 \\
19.49\end{array}$ & $\begin{array}{l}7.41 \\
9.12 \\
5.79\end{array}$ \\
\hline $\begin{array}{l}\text { Polynomial } \\
\text { model } 3\end{array}$ & $\begin{aligned} P_{\text {core }, A}= & \left(8.46 \times 10^{-8}\right) V_{a}^{6}-\left(2.94 \times 10^{-5}\right) V_{a}^{5}+0.0009 V_{a}^{4}+0.90 V_{a}^{3}-158.68 V_{a}^{2}+10624 V_{a}+\left(5.94 \times 10^{-8}\right) V_{b}^{6} \\
& -\left(2.39 \times 10^{-5}\right) V_{b}^{5}+0.002 V_{b}^{4}+0.26 V_{b}^{3}-71.31 V_{b}^{2}+5321.3 V_{b}-\left(9.71 \times 10^{-8}\right) V_{C}^{6}+\left(3.33 \times 10^{-5}\right) V_{C}^{5} \\
& -0.0007 V_{b}^{4}-1.12 V_{C}^{3}+192.01 V_{C}^{2}-12704 V_{C}-89092 \\
P_{\text {core }, B}= & \left(-7.35 \times 10^{-8}\right) V_{a}^{6}+\left(1.27 \times 10^{-5}\right) V_{a}^{5}+0.007 V_{a}^{4}-2.52 V_{a}^{3}+336.98 V_{a}^{2}-20573 V_{a}-\left(3.20 \times 10^{-7}\right) V_{b}^{6} \\
& +0.0001 V_{b}^{5}-0.014 V_{b}^{4}-1.27 V_{b}^{3}+374.02 V_{b}^{2}-28211 V_{b}-\left(5.17 \times 10^{-8}\right) V_{C}^{6}+\left(5.00 \times 10^{-5}\right) V_{C}^{5} \\
& -0.02 V_{C}^{4}+3.31 V_{C}^{3}-326.21 V_{C}^{2}+16714 V_{C}+8.6378 \times 10^{5} \\
P_{\text {core }, C}= & \left(-1.32 \times 10^{-7}\right) V_{a}^{6}+\left(9.26 \times 10^{-5}\right) V_{a}^{5}-0.03 V_{a}^{4}+4.08 V_{a}^{3}-346.85 V_{a}^{2}+15645 V_{a}+\left(2.8676 \times 10^{-7}\right) V_{b}^{6} \\
& -0.0001 V_{b}^{5}+0.008 V_{b}^{4}+1.92 V_{b}^{3}-412.67 V_{b}^{2}+29093 V_{b}+\left(1.94 \times 10^{-7}\right) V_{C}^{6}-0.0001 V_{C}^{5} \\
& +0.031 V_{b}^{4}-4.17 V_{C}^{3}+317.56 V_{C}^{2}-12844 V_{C}-8.0637 \times 10^{5}\end{aligned}$ & 1.08 & 13.33 & 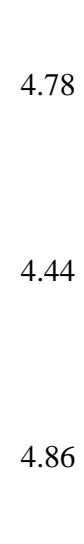 \\
\hline $\begin{array}{l}\text { Neural network } \\
\text { model III }\end{array}$ & $\begin{array}{l}P_{\text {core }, A} \\
P_{\text {core }, B} \\
P_{\text {core }, C}\end{array}$ & & $\begin{array}{r}9.78 \\
9.25 \\
11.21\end{array}$ & $\begin{array}{l}4.02 \\
4.29\end{array}$ \\
\hline
\end{tabular}

the total iron loss, the error rate of the neural network model set up by this study is lower than that of polynomial method, this is especially true in the prediction of the total iron loss of transformer under three phase equilibrium system, the prediction error rate can be reduced by $50 \%$. Therefore, neural network is more suitable to be used in the estimation of the transformer iron loss within dynamic power system.

\section{REFERENCE}

1. Alonso, G. and Antonio, J., "A new method for calculating of leakage reactances and iron losses in transformers," Proceedings of the Fifth International Conference on Electrical Machines and Systems, Vol. 1, pp. 178-181 (2001).

2. Batista, A. J., Fagundes, J. C. S., and Viarouge, P., "An automated system for core loss measurement and characterization: a useful tool for high frequency magnetic components design," IEEE International Symposium on Industrial Electronics, Vol. 2, pp. 540-545 (1998).
3. Becker, B., Grotstollen, H., and Heinemann, L., "Computer aided design and modeling of high frequency magnetic components," APEC '95. Applied Power Electronics Conference and Exposition, Vol. 1, pp. 335-341 (1995).

4. Chen, T.-H., Chen, M.-S., Inoue, T., Kotas, P., and Chebli, E. A., "Three phase cogenerator and transformer models for distribution system analysis," IEEE Transactions on Power Delivery, Vol. 6, pp. 1671-1681 (1991).

5. Doulamis, A. D. and Doulamis, N. D., "A neural network-genetic algorithm scheme for optimal grouping of individual cores in three phase distributed transformers," 2002 14th International Conference on Digital Signal Processing, Vol. 2, pp. 1061-1064 (2002).

6. Doulamis, N. D. and Doulamis, A. D., "Optimal distribution transformers assembly using an adaptable neural network-genetic algorithm scheme," IEEE International Conference on Systems, Man and Cybernetics, Vol. 5, p. 6 (2002).

7. Elleuch, M. and Poloujadoff, M., "Analytical model of iron losses in power transformers," IEEE Transactions on Magnetics, Vol. 39, pp. 973-980 (2003).

8. Elleuch, M. and Poloujadoff, M.,"New transformer model including joint air gaps and lamination anisotropy," IEEE Transactions on Magnetics, 
Vol. 34, pp. 3701-3711 (1998).

9. Georgilakis, P. S., Doulamis, N. D., Doulamis, A. D., Hatziargyriou, N. D., and Kollias, S. D., "A novel iron loss reduction technique for distribution transformers based on a combined genetic algorithm - neural network approach," IEEE Transactions on Systems, Man and Cybernetics, Part C, Vol. 31, pp. 16-34 (2001).

10. Georgilakis, P. S., Hatziargyriou, N., and Paparigas, D., "AI helps reduce transformer iron losses," IEEE Computer Applications in Power System, Vol. 12, pp. 41-46 (1999).

11. Georgilakis, P. S., Hatziargyriou, N., Paparigas, D., Bakopoulos, J., "On-line combined use of neural networks and genetic algorithms to the solution of transformer iron loss reduction prolem," International Conference on Electric Power Engineering, pp. 155 (1999).

12. Luczkowski, R. and Muszynski, R., "AC machine and transformer magnetic circuit model for iron loss calculation at converter feeding," 2003 IEEE International Conference on Industrial Technology, Vol. 1, pp 483-488 (2003).

13. Mechler, G. F. and Girgis, R. S., "Calculation of spatial loss distribution in stacked power and distribution transformer cores," IEEE Transactions on Power Delivery, Vol. 13, pp. 532-537 (1998).

14. Moses, A. J., "Comparison of transformer loss prediction from computed and measured flux density distribution," IEEE Transactions on Magnetics,
Vol. 34, pp. 1186-1188 (1998).

15. Nyenhuis, E. G., Mechler, G. F., and Girgis, R. S., "Flux distribution and core loss calculation for single phase and five limb three phase transformer core designs," IEEE Transactions on Power Delivery, Vol. 15, pp. 204-209 (2000).

16. Pedra, J., Corcoles, F., Sainz, L., and Lopez, R., "Harmonic nonlinear transformer modeling," IEEE Transactions on Power Delivery, Vol. 19, pp. 884-890 (2004).

17. Shimoji, H., Horibe, T., and Enokizono, M., "The two-dimensional magnetic property on the special single-phase transformer core," Digest of Technical Papers, Magnetics Conference, pp. DU11 (2002).

18. So, E., Arseneau, R., and Hanique, E., "No-load loss measurements of power transformers under distorted supply voltage waveform conditions," IEEE Transactions on Instrumentation and Measurement, Vol. 52, pp. 429-432 (2003)

19. Stensland, T., Fuchs, E. F., Grady, W. M., and Doyle, M. T., "Modeling of Magnetizing and core-loss current in single-phase transformers with voltage harmonics for use in power flow," IEEE Transactions on Power Delivery, Vol. 12, pp. 768-774 (1997).

20. Tran-Quoc, T. and Pierrat, L., "Correction of the measured core losses under distorted flux," IEEE Transactions on Magnetics, Vol. 33, pp. 20452048 (1997). 